\title{
Obituary
}

\section{Francesco Lo Coco, a distinguished hema- tologist and a friend}

Professor Francesco Lo Coco passed away on March $3^{\text {rd }}$. The hematology community has lost a dear friend, a respected colleague and an enlightened scientist. Francesco was a brilliant student of Franco Mandelli and made a substantial contribution to the field of translational and clinical research, especially the advancement of the treatment of acute promyelocytic leukemia and molecular diagnostics in acute leukemia. He was one of the leaders of the Italian Hemato-Oncology Cooperative Group GIMEMA, member of the Executive Board of the Italian Society of Hematology and President of the Italian Society of Experimental Hematology from 2000 to 2002. Prof. Lo Coco received much recognition and many awards for his work, in particular the José Carreras Award from the European Hematology Association in 2018.

Francesco was truly a friend in the best sense. He was warm, sensitive, open-minded and helpful. His friends know that he was especially proud of his son Gaetano, a young orchestral conductor, with whom he enjoyed a particularly close relationship.

On behalf of the SIE, SIES and GIMEMA:

Prof. Paolo Corradini, President of SIE

Prof. Pellegrino Musto, President of SIES

Prof. Marco Vignetti, President of GIMEMA

doi: 10.3324/haematol.2019.222356

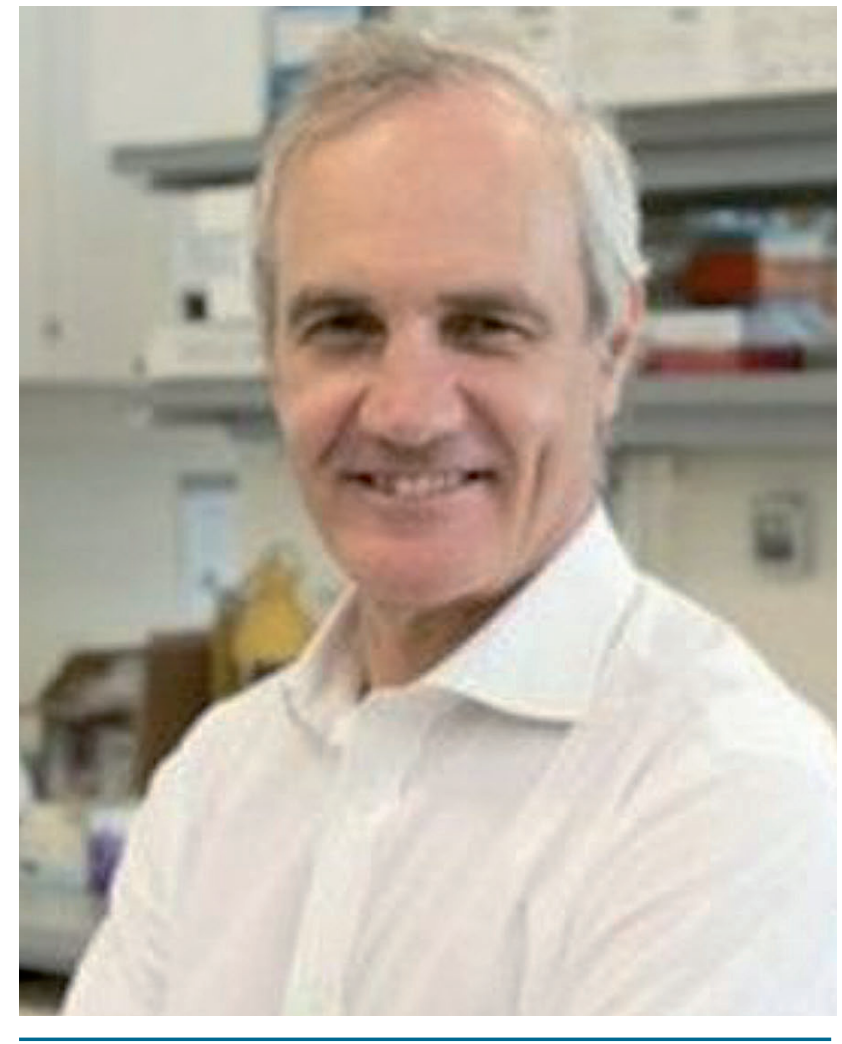

Francesco Lo Coco. 